Review Article

\title{
Mesenchymal Stromal Cells and Cutaneous Wound Healing: A Comprehensive Review of the Background, Role, and Therapeutic Potential
}

\author{
Michael S. Hu (D), Mimi R. Borrelli, H. Peter Lorenz, Michael T. Longaker, and Derrick C. Wan \\ Hagey Laboratory for Pediatric Regenerative Medicine, Division of Plastic and Reconstructive Surgery, Department of Surgery, \\ Stanford University School of Medicine, Stanford, CA, USA
}

Correspondence should be addressed to Derrick C. Wan; dwan@stanford.edu

Received 9 February 2018; Accepted 9 May 2018; Published 20 May 2018

Academic Editor: Huseyin Sumer

Copyright (C) 2018 Michael S. Hu et al. This is an open access article distributed under the Creative Commons Attribution License, which permits unrestricted use, distribution, and reproduction in any medium, provided the original work is properly cited.

\begin{abstract}
Cutaneous wound repair is a highly coordinated cascade of cellular responses to injury which restores the epidermal integrity and its barrier functions. Even under optimal healing conditions, normal wound repair of adult human skin is imperfect and delayed healing and scarring are frequent occurrences. Dysregulated wound healing is a major concern for global healthcare, and, given the rise in diabetic and aging populations, this medicoeconomic disease burden will continue to rise. Therapies to reliably improve nonhealing wounds and reduce scarring are currently unavailable. Mesenchymal stromal cells (MSCs) have emerged as a powerful technique to improve skin wound healing. Their differentiation potential, ease of harvest, low immunogenicity, and integral role in native wound healing physiology make MSCs an attractive therapeutic remedy. MSCs promote cell migration, angiogenesis, epithelialization, and granulation tissue formation, which result in accelerated wound closure. MSCs encourage a regenerative, rather than fibrotic, wound healing microenvironment. Recent translational research efforts using modern bioengineering approaches have made progress in creating novel techniques for stromal cell delivery into healing wounds. This paper discusses experimental applications of various stromal cells to promote wound healing and discusses the novel methods used to increase MSC delivery and efficacy.
\end{abstract}

\section{Introduction}

An open wound is a loss of continuity of the epidermis, caused by mechanical, chemical, biological, or thermal injuries. Open wounds can be superficial involving the epidermis and varying degrees of dermis, or full thickness extending to the subcutaneous layer. Cutaneous wound healing is a highly organized physiological process that restores the integrity of the skin following injury. It involves the interplay between various populations of cells and is typically categorized into three overlapping phases: inflammation, proliferation, and maturation [1-3].

The highly coordinated wound repair process is susceptible to interruption or failure by multiple factors which can result in nonhealing wounds. Chronic wounds are defined as those which persist for at least three months and are generally classified as vascular, diabetic, or pressure ulcers. They usually occur due to characteristics of the wound or patient physiology or as a complication of a disease process, all of which prolong or exacerbate the inflammatory process and prevent dermal or epidermal cells responding to regenerative stimuli [4]. Cutaneous injury that penetrates beyond the epidermis in adult human skin is repaired by a highly evolved fibroproliferative response that quickly restores the skin barrier but results in the formation of a scar. Scarred skin lacks dermal appendages, such as sebaceous glands, hair follicles, and sensory nerve receptors [1], and has a reduced tensile strength [5], which alter its visual appearance and impact its normal functions.

Wound healing represents a significant challenge in plastic surgery. Chronic wounds cause substantial patient morbidity, with detrimental effects on patient quality of life, increasing pain, stress, depression, and social isolation [6]. More than six million people suffer with chronic skin 
wounds every year in the United States alone [7], and with the aging population and increased incidence of diabetes and obesity, this disease burden is increasing [8]. Current standards of wound care focus on identifying and removing precipitating or aggravating factors with the hope of reducing inflammation and allowing the healing cascade to proceed $[1,9]$. These treatments are often expensive, time-consuming, and inefficient, and more than $50 \%$ of chronic wounds are refractory to conventional treatments [10]. Despite the deleterious consequences of fibrosis and scar tissue formation, there are no effective treatments for scarring [10]. The annual worldwide market for advanced wound care products to reduce scarring and promote healing of long-term wounds is in excess of $\$ 20$ billion [8].

Given the significant medical and economic burdens, there is a paramount need to develop therapies to overcome the current barriers in wound care. A new therapy for wound healing and regeneration gaining momentum in the past few years is the use of mesenchymal stromal cells (MSCs). MSCs exist in normal skin and play a critical role in wound healing; therefore, application of exogenous MSCs was proposed to promote regenerative healing of wounded skin [11]. This chapter addresses the definition of MSCs, their role in endogenous wound healing, the therapeutic use of MSCs, and the mechanisms by which MSC-based therapies may impact skin healing outcomes.

\section{Mesenchymal Stromal Cells (MSCs)}

MSCs are progenitor cells of mesodermal origin. MSCs were first isolated from bone marrow in the 1970s [12] by their inherent ability to adhere to tissue culture surfaces like plastic. The cells were notable for their spindle-like shape, the capacity to derive colonies from single cells ("colony forming units-fibroblastic," CFUs-F), as well as their ability to differentiate into adipocytes, chondrocytes, osteocytes, and fibrous tissue, in vitro and in vivo. Supporting experimental evidence for these nonhematopoietic multipotent stromal cells was widely reproduced in bone marrow [13], and subsequently, similar cells were described in a range of adult tissues, including adipose tissue $[14,15]$ and dermal skin tissue [16], as well as from embryonic and fetal sources, such as the amniotic membrane [17], umbilical cord [18-22], and umbilical cord blood/Wharton's jelly [23, 24] (Figure 1).

MSCs have been challenging to precisely define, as the field is complicated by inconsistencies with MSC nomenclature and agreed identifying criteria. MSCs were first termed "osteogenic stem cells" or "bone marrow stromal stem cells" and later labeled "mesenchymal stem cells" [25] and "stromal progenitor cells" [26]. Concerns in the scientific community that these cells are not truly stem cells, given the lack of evidence demonstrating self-renewing capacity in vivo [26-28], the International Society for Cellular Therapy (ISCT) in 2005 [27] stated "that fibroblast-like plasticadherent cells, regardless of the tissue from which they are isolated, be termed multipotent mesenchymal stromal cells, while the term mesenchymal stem cell is only used for cells that meet specified stem cell criteria. The widely recognized acronym, MSC, may be used for both cell populations as is the current practice." Despite this statement, the term "mesenchymal stem cell" remains widely used and a systematic analysis of bone marrow-derived MSCs (BMSCs) by the European consortium Genostem reported that MSCs are capable of self-renewal, providing evidence that they are stem cells [29]. The stem cell behavior of MSCs remains debated.

The single most characteristic feature of MSCs is their capacity to develop into adipocytes, chondroblasts, and osteoblasts in vitro. Demonstrating this trilineage differentiation potential in vitro is often performed to confirm MSC identity [30]. However, some reports indicate that MSCs are able to develop into nonmesenchymal lineages, like epidermal and neuronal cells [31-34]. This postulated transgermal potential remains highly controversial; it may be exceedingly rare in vivo $[35,36]$, and cell fusion may account for observed plasticity [37].

There is no specific cell surface marker unique to MSCs, and MSCs are often isolated by "adherence selection." There is considerable heterogeneity in the expression of cell surface markers between MSC populations, and surfaceome is influenced by rodent strain, MSC isolation and expansion methods [38], and culture conditions [39]. The ISCT attempted to resolve challenges in confirming MSC identity by proposing three minimal criteria for defining human MSCs: (1) the cells must be plastic-adherent when maintained in standard culture conditions using tissue culture flasks; (2) $\geq 95 \%$ of the population must express CD105, CD73, and CD90 and $\leq 2 \%$ must not express CD45, CD34, CD14, CD11b, CD79 $\alpha$, or CD19, and HLA class II surface molecules; and (3) the cells must be able to differentiate into osteoblasts, adipocytes, and chondroblasts under standard in vitro differentiating conditions [40].

There is a growing body of evidence to suggest that many of the cells exhibiting in vitro characteristics of MSCs are identical to or derived from pericytes in vivo [41-44]. Pericytes are cells located within the vascular basement membrane of microvessels and capillaries throughout the body, which may indicate there is a common precursor cell type in a wide variety of tissues.

\section{Endogenous MSCs in Wound Healing}

Endogenous cutaneous MSCs include dermal papilla cells (DPC), at the base of the hair follicle, and the dermal sheath cells (DSC), which surround hair follicle units. DPCs are primarily involved in modulating hair follicle cycling $[45,46]$, while the DSCs are thought to play a critical role in replacing the dermis in response to injury by differentiating into wound healing fibroblasts [47] (Figure 2). Additional dermal MSCs may be located in the interfollicular dermis $[48,49]$, and the perivascular pericytes may act as MSCs in vivo [50, 51]. Additionally, cutaneous wounding may activate MSCs residing in the adipose tissue. Mature and precursor adipocytes populate the wounded area during the proliferative phase of wound healing, in parallel with fibroblasts. The impaired wound healing of lipoatrophic mice suggests that adipose tissue MSCs have a role in the recruitment of fibroblast and dermal reconstruction. [52] Finally, the BMSCs are also thought to contribute to cutaneous wound 


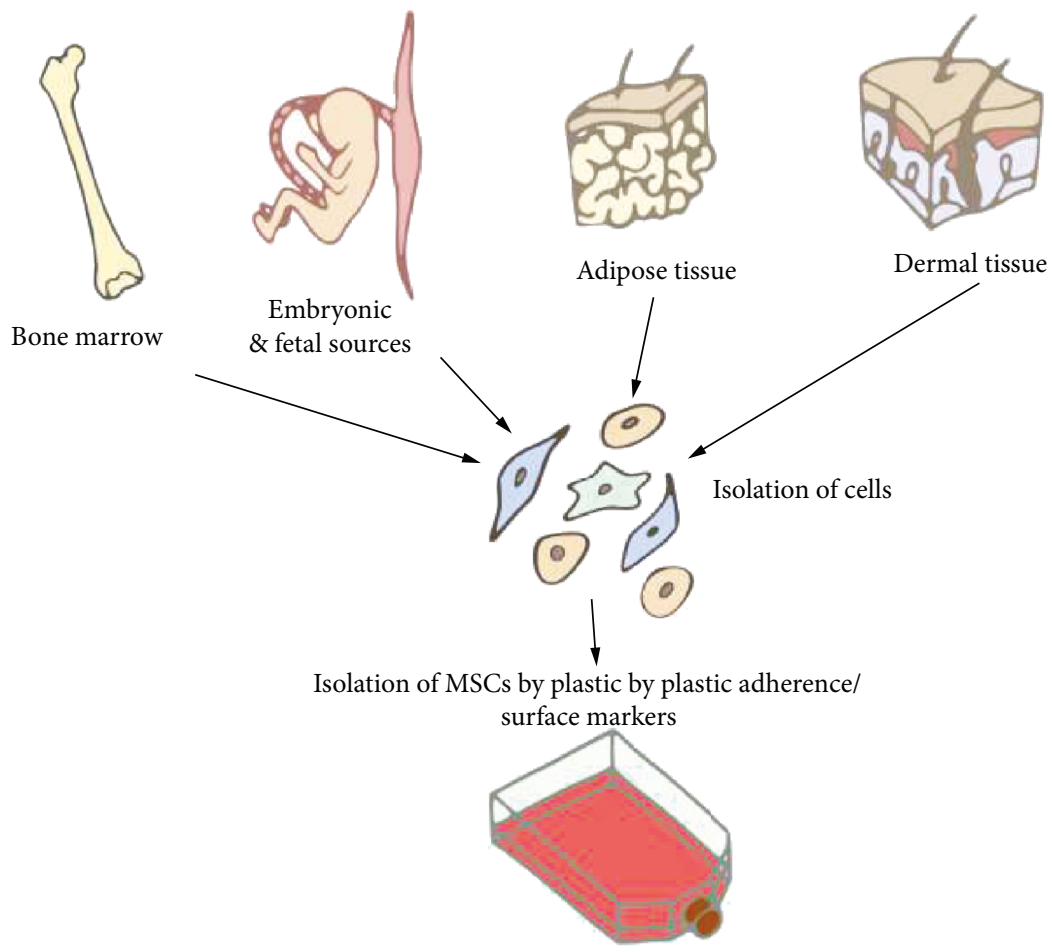

FIGURE 1: Mesenchymal stromal cells have been isolated from adult tissue including adipose tissue, dermal tissue, and bone marrow, as well as from embryonic and fetal sources. MSCs have been isolated from tissue by their ability to adhere to plastic or by their surface antigen expression (e.g., $\mathrm{CD}_{105^{+}}, \mathrm{CD}^{+} 3^{+}$, and $\mathrm{CD} 90^{+}$).

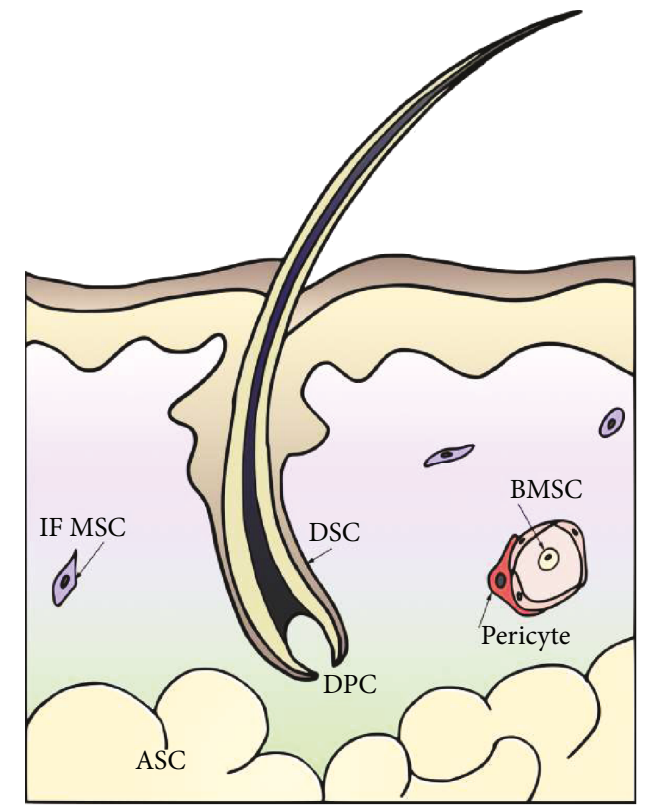

FIgURE 2: The MSCs involved in normal wound healing. ASC $=$ adipose-derived MSC; $\mathrm{BMSC}=$ bone marrow-derived MSC; $\mathrm{DPC}=$ dermal papilla cell; $\mathrm{DSC}=$ dermal sheath cell; IF MSC $=$ interfollicular MSC.

healing and are reported to be recruited to wounded tissue in early inflammation and maintained in the reconstructed dermal tissue [53-56].

\section{Therapeutic Use of MSCs in Wound Healing}

MSCs have been exogenously applied to wounds to exploit their physiological therapeutic actions in normal wound healing, and regardless of the caveats in their identity or source, MSCs have been reported to have positive effects on both wound healing and scarring. MSCs have a wide differentiation potential, making them attractive treatment options in regenerative medicine and, over the past decade, have rapidly emerged as treatment of acute and chronic wounds.

Most of the evidence of MSCs in wound healing comes from BMSCs used in animal models, with only a small number of published clinical studies. In an initial case series $(n=3)$, bone marrow aspirate and, in three additional treatments, cultured BMSCs were applied to chronic wounds and were able to decrease wound size and increase dermal vascularity and thickness in histology [57]. In a second case series, autologous BMSCs topically applied to acute surgical wounds and chronic lower-extremity wounds using fibrin spray accelerated healing of acute surgical wounds $(n=5)$ and significantly decreased wound size of chronic venous and diabetic ulcer wounds $(n=6)$ at 20 weeks. Histologically, the MSCs had migrated into the upper layers of the wound bed and differentiated into cells with a fibroblast phenotype. The surface density of MSCs correlated with the reduction in ulcer size [58]. In one of the largest case series, 20 chronic, nonhealing wounds $(n=13)$ were treated with autologous BMSCs impregnated onto a collagen sponge, and ninety percent of the wounds healed completely [59]. 
A randomized study in 2009 found that cultured autologous BMSCs simultaneously administered topically onto 24 chronic, nonhealing ulcers of the lower extremities and via intramuscular injection into the affected limb significantly decreased wound size (72\% versus 25\%) and decreased ulcer-associated wound pain at 12 weeks, compared to standard wound care [60]. A second randomized study injected autologous BMSCs intramuscularly into the affected limb and reported improved pain-free walking at 24 weeks and significantly increased ulcer healing rate compared to control treatment [61].

BMSCs are obtained from bone marrow aspiration, which is a safe but painful and invasive procedure, associated with complications such as infection and hemorrhage [18]. Additionally, bone marrow is a limited resource; there is an age-dependent reduction in cell number [62]. The longterm growth and differentiation potential of BMSCs in vitro may be limited [63]. Therefore, identification and characterization of alternative sources of human MSCs for wound healing is important. Several different MSCs have been applied to wounds in preclinical investigations of wound healing, including adipose-derived stromal cells (ASCs), dermal MSCs [64], and MSCs from amniotic fluid and umbilical cord. ASCs and dermal MSCs are abundantly available in fat and skin and can be harvested with minimally invasive procedures, and their use lacks ethical controversies making them good alternatives to BMSCs. ASCs and dermal MSCs have similar biological characteristics, immunogenicity, and differentiation potential to BMSCs [15, 16, 65-68], although the clonogenicity and proliferation capacity in long-term cultures of dermal sheath MSCs may exceed that of BMSCs [67]. Additionally, the paracrine expression profiles of all three MSC types vary slightly, and this can differentially affect wound healing. ASCs, for example, may be the preferred MSC population for augmenting angiogenesis [69].

ASCs show promising outcomes in wound healing studies in vitro [70,71] and in vivo in animal models [72-76] and are currently being evaluated in clinical trials for their potential to treat burn wounds and ulcers. An initial study has shown that human ASCs, obtained from the debridement of burned artificial dermis, were associated with a high degree of success in healing the wounds of patients who suffered chronic radiation injuries [77]. Likewise, dermal MSCs show beneficial effects on wound healing, both in culture and in animal models $[67,78]$. In clinical trials, autologous scalpend terminal hair follicles grafted into nonhealing leg wounds $(n=10)$ reduced wound size at 18 weeks, with histological evidence of re-epithelialization and vascularization [79]. A randomized controlled trial (RCT) reported that skin grafts containing follicles significantly reduced wound size compared to skin grafts without hair follicles in chronic leg ulcers $(n=19)$ [80].

These promising clinical studies indicate that MSC-based therapies are safe and potentially efficacious, with no indication that any particular MSC tissue origin has an advantage for wound healing over any other [81]. Currently, the clinical trials are few in number and limited by sample size and longterm follow-up. MSCs are thought to exert their therapeutic effects through a multitude of actions, on various cell types, and at all of the phases of the wound healing cascade [81-83]. Current understanding of the mechanisms of MSCs on wound healing and scar minimizing are addressed in the following section.

4.1. MSCs in Wound Healing: Inflammation. The first phase of wound healing is the inflammatory phase, which begins at the time of wounding. Activation of the coagulation cascade initiates the release of cytokines and chemokines which stimulate the chemotaxis of neutrophils, followed by macrophages and later lymphocytes, into the wound for debridement. These inflammatory cells, in turn, secrete growth factors and provisional matrix proteins which promote the recruitment of neighboring epidermal and dermal cells to the wound bed [84]. Inflammation controls microbial invasion and clears the wound site of cellular debris; however, prolonged inflammation can result in the formation of scar tissue [85-87]. On the other hand, an absent or inadequate inflammatory response can give rise to chronic, nonhealing wounds $[88,89]$.

Exogenous BMSCs home to areas of tissue injury. In vivo tracing of the fluorescently labeled BMSCs injected into lethally irradiated mice indicates that BMSCs migrate preferentially to areas of cutaneous injury [90]. In vitro, human BMSCs show chemotaxis towards inflammatory wound healing cytokines and growth factors, including platelet-derived growth factor (PDGF), insulin-like growth factor-1 (IGF-1), interleukin $1 \beta$ (IL-1 $\beta)$, IL-8, interferon- $\gamma$ (IFN- $\gamma$ ), stromal cell-derived factor-1 (SDF-1), and tumor necrosis factor $\alpha$ (TNF $\alpha$ ) [91-93]. These migrating BMSCs upregulate chemokine receptors, such as macrophage-derived chemokine (MDC) receptors CCR2, CCR3, and CCR4; tyrosine kinase receptors PDGF receptor and IGF-R; and RANTES (chemokine ligand 5 (CCL5)), which likely coordinate MSC migratory activity [93-95].

Once present at sites of injury, MSCs exert immunosuppressive effects. Wounds treated with MSCs have lower numbers of inflammatory cells and proinflammatory cytokines, such as IL-1 and TNF $\alpha$ [96]. Upon exposure to proinflammatory cytokines, including IFN- $\gamma$, TNF $\alpha$, IL- $1 \alpha$, and IL- $1 \beta$, the immunosuppressive phenotype of MSCs becomes activated, and they begin to express chemokines and inducible nitric oxide synthase (iNOS), which suppress $\mathrm{T}$ cell responsiveness to inflammation. In response to MSC activity, $\mathrm{T}$ cells secrete less IFN- $\gamma$ and more IL-4, and the number of regulatory T cells increases [97-99]. MSCs also regulate the proliferation, differentiation, and function of B cells [100] and natural killer cells [101], causing natural killer cells to secrete less IFN- $\gamma[102,103]$.

MSCs also suppress the proinflammatory activity of myeloid cells including monocytes [104, 105], macrophages [106-110], and granulocytes [111]. Dendritic cells are modified to secrete less TNF $\alpha$ and more IL-10, and their migration, maturation, and antigen presentation activity is lessened $[102,103]$. The MSC-conditioned medium is a chemoattractant for macrophages, through the production of macrophage inflammatory protein-1alpha and beta [112], and MSCs skew the phenotype of macrophages toward an anti-inflammatory phenotype M2, characterized by 
increased phagocytic ability and the upregulation of antiinflammatory cytokines such as IL-12 and TNF $\alpha$ [109, $113,114]$. This macrophage reprogramming is thought to occur through the release of prostaglandin $\mathrm{E}_{2}$ that acts on the macrophages through the prostaglandin EP2 and EP4 receptors [106-108]. M2 macrophages promote wound healing by augmentation of fibroblast proliferation and suppress inflammation by inhibiting T cell proliferation [107]. BMSCs and the conditioned medium of BMSCs have also been found to inhibit bacterial growth, in part by secretion of the antimicrobial human cathelicidin hCAP-18/LL-37 protein [115].

4.2. MSCs in Wound Healing: Proliferation. The proliferative phase predominates wound healing after two to three days, characterized by the formation of granulation tissue, composed of proliferating keratinocytes and fibroblasts, migrating epidermal cells, and newly synthesized extracellular matrix (ECM), resulting in re-epithelialization and angiogenesis [84, 116-118]. Wounds treated with BMSC and ASC have accelerated re-epithelialization, angiogenesis, and granulation tissue formation [94, 119-125]. Differentiation and paracrine signaling have both been implicated as mechanisms by which BMSCs exert their beneficial effects in the proliferation phase.

Some studies suggest MSCs may differentiate into a variety of skin cells in the healing wounds following transplantation. In vivo studies tracing fluorescently labeled BMSCs injected intravenously or topically applied to the wounded skin of mice report the presence of fluorescent cells upon healing that are positive for markers of dermal fibroblasts, endothelial cells, pericytes [126], and epidermal keratinocytes [94, 121, 127]. BrdU-labeled adult MSCs cocultured with heat-shocked sebaceous gland cells, differentiated into sebaceous glands in skin adjacent to the wound [123]. The percentage of BMSC engraftment in the wound, however, is low and decreases with time. Additionally, most studies have concluded evidence of MSC differentiation based on colocalization of green fluorescent protein (GFP) with specific cell phenotype markers; however, colocalization could also occur by MSC fusion to local wound resident cells [128]. Other authors have reported that there is no evidence that MSCs differentiate into phenotypes typical of resident cutaneous cells in the healing skin wound [120].

There is growing evidence that paracrine signaling is the predominant mechanism by which MSCs enhance wound repair. Acellular conditioned medium from BMSCs and ASCs applied to cutaneous wounds of mice accelerated re-epithelialization and wound repair [73, 125, 129]. Proteomic analyses reveal that BMSCs, ASCs, DPCs, DSCs, and umbilical MSCs secrete many known mediators of tissue repair, including growth factors, cytokines, and chemokines $[69,129,130]$. Secreted proangiogenic factors are likely to increase the density of microvessels and cutaneous wound microcirculation and include vascular endothelial growth factor (VEGF), angiopoietin-1, angiogenin, and leptin $[71,76,96,125,131]$. Levels of angiogenin and VEGF levels are comparable between MSC populations, but DPCs and DSCs release higher amounts of leptin [69]. The growth factors released include IGF-1, PDGF, epidermal growth factor (EGF), keratinocyte growth factor, basic fibroblast growth factor (bFGF), SDF-1, erythropoietin, transforming growth factor- $\beta$ (TGF- $\beta$ ), and hepatocyte growth factor (HGF) $[69,71,121,129,130]$. These growth factors promote migration and proliferation of endothelial cells, epidermal keratinocytes, and dermal fibroblasts in vitro and significantly influence wound re-epithelialization in vivo [71, 73, $125,129,132,133]$. ASCs and amniotic fluid-conditioned media facilitate the production of ECM components such as collagen I by dermal fibroblasts, and this is thought to be mediated via the TGF- $\beta /$ SMAD2 pathway $[71,125,130$, 134-136]. MSCs thus have a potent secretome capable of influencing the activation, migration, and proliferation of different cells involved in the wound healing process to promote angiogenesis, epithelialization, and fibroproliferation.

4.3. MSCs in Wound Healing: Remodeling and Maturation. Upon wound closure, the injured site undergoes remodeling and maturation phases. This final phase of wound healing can last up to two years depending on wound severity. The ECM synthesized during the proliferative phase is laid down in a disorganized manner. During remodeling, ECM molecules are realigned and cross-linked by fibroblasts. Fibroblasts also replace collagen III with collagen I. The wounds gradually contract as fibroblasts, stimulated by TGF- $\beta 1$ or $\beta 2$ and PDGF, assume a contractile myofibroblast phenotype and deposit smooth muscle actin [137, 138]. Cells and blood vessels that are no longer required are removed via matrix metalloproteinase- (MMP-) mediated remodeling. Eventually, remodeling leads to the formation of an acellular scar $[2,139]$.

MSC treatment increases wound tensile strength [119], reduces scarring [140], reduces wound contraction [124], and increases collagen expression [141]. Prolonged inflammation can induce fibrosis, and the anti-inflammatory action of MSCs may be responsible for their antifibrotic effects. The relative increase in the ratio of anti-inflammatory M2 to proinflammatory M1 macrophages may help to reduce scarring, as increased M1 macrophage is thought to be a major regulator of impaired wound healing and tissue fibrosis [142]. Reduced scarring may also be a result of accelerated wound closure, improved angiogenesis, and modified collagen deposition. The paracrine signaling of MSCs may also promote an antiscarring environment. MSCs secrete high levels of VEGF and HGF and maintain a higher ratio of TGF- $\beta 3$ to TGF- $\beta 1$. bFGF and HGF enhance the regeneration of dermis in acute incisional wounds [143]. Increased VEGF is associated with scarless repair [144], as is neutralization of TGF- $\beta 1$ and TGF- $\beta 2$ or addition of TGF- $\beta 3$ [145]. Hypoxic conditioned medium of placentaderived MSC protects against scar formation through increased production of IL-10 and through the inhibition of the proliferation and migration of fibroblasts [146]. Additionally, BMSCs appear to be responsible for the secretion of collagen type III [56], and a higher collagen type III : type I ratio is associated with the scarless wounds characteristic of healing in fetal tissue [147]. 


\section{Optimizing MSC Treatment}

Optimizing MSC engraftment in the cutaneous wounds is critical to achieving maximal clinical benefit. There is considerable heterogeneity in the delivery protocols, wound models, and MSC populations between published studies making it difficult to determine the impact of timing of delivery, number of cells delivered, and site of delivery on MSC engraftment. MSCs are effective in clinical and preclinical studies when applied immediately after cutaneous wounding [94, 120-123], within 24 hours of injury [119], and when applied to chronic wounds [58, 60, 77, 79, 148]. MSCs have been successfully administered systemically via intravenous injection $[94,119]$ and locally via direct intradermal injection [121], or through the use of phosphate-buffered saline (PBS) [120], matrigel [121], fibrin polymer [58], or hydrogel seeding [126]. Additionally, MSC-conditioned medium is effective alone $[73,125,129]$ and has the advantage of circumventing challenges with MSC engraftment.

Direct injection or topical administration of MSCs through gel matrices can be detrimental for cell survival. Impregnating scaffolding materials with MSCs may provide a microenvironment more suitable for cell adhesion, proliferation, and differentiation [149]. Scaffolds can be made of natural biomaterials, like collagen and hyaluronic acid, the major constituents of the ECM, as well as fibrin, a protein essential for coagulation. These biomaterial scaffolds have high biocompatibility [3] and, in preclinical studies, enhance wound epithelialization and granulation and downregulate inflammation [150, 151]. MSCs used in combination with collagen-based dermal substitutes promote the migration of cells to wounded skin and vascularization of the scaffold in vivo in mice [152]. BMSCs and umbilical cord MSCs cocultured with HaCT, a keratinocyte cell line, distributed on collagen scaffolds, distributed more homogenously within the wound, and expressed higher numbers of ECM proteins and growth factors compared to MSCs applied on scaffolds without collagen, indicating that collagen-based scaffolds may direct cell proliferation and ECM remodeling [153]. MSCs delivered in collagen- and fibrin-based biomedical devices show promise in nonhealing and chronic wounds in clinical studies [154]. Collagen sponges impregnated with BMSCs ( $n=20$ patients) completely healed chronic burns, lower-extremity ulcers, and decubitus ulcers [59]. BMSC delivered on a fibrin glue and collagen matrix also completely or significantly closed diabetic ulcers [155]. Scaffolds can also be made of polysaccharides like chitosan, which have antimicrobial and homeostatic activity, and are able to stimulate the proliferation of fibroblasts, tissue granulation, re-epithelialization, and collagen deposition [3]. Synthetic polymers, such as those made of polyethylene glycol, are also biocompatible and biodegradable, and their properties, such as strength and degradation rate, can easily be manipulated [156]. Growth factors and therapeutic agents can be used with the scaffolds. MSCs in porcine skin substitute decreased wound size, and FGF could be delivered to further accelerate wound healing [157]. Porous collagen scaffolds loaded with the chemotactic cue stromal cell-derived factor- $1 \alpha$ in vivo promoted the recruitment of MSCs to the injured area [158]. Additionally, applying MSCs with other skin cells may reflect the multicellular composition of skin and promote an environment more conducive to healing. Coculturing human epidermal skin cells and DPCs on a porcine acellular matrix produced a more structured multilayered stratified epidermis when compared with the culture of either of these cells or dermal fibroblasts alone [159].

Recent technological advancements have led to the creation of micro- or nanostructured scaffolds by mechanisms such as electrospinning and freeze drying. These scaffolds can provide mechanical support and protection to the injured areas, with physical characteristics, such as size, network organization, and mechanical properties, that precisely mimic native skin. Electrospun nanofibers of collagen and poly(lactic-co-glycolic acid) (PLGA) seeded with BMSCs promoted collagen synthesis and re-epithelialization in full-thickness skin wounds in a rat model [160]. Bilayer nanofibrous polymer fibers of poly( $\varepsilon$-caprolactone-co-lactide)/poloxamer (PLCL/poloxamer) combined with dextran and gelatin substrates were found to more accurately mimic the multilayer structure of the skin [161]. Nanofibers of polyvinyl alcohol (PVA), gelatin, and azide were able to promote the differentiation of ASCs to keratinocytes [162]. BMSCs cultured on electrospun nanofibers of collagen and poly(l-lactic acid-co-e-caprolactone) (PLLCL) had an increased proliferation rate, and their fibroblastic morphology gradually progressed toward that one of epidermal cells [163]. Chitosan-electrospun mats with cellulose or chitin nanocrystals are biocompatible and noncytotoxic scaffolds and may promote ASC proliferation $[164,165]$. Polymer structures made of poly(3-hydroxybutyrate-co-hydroxyvalerate) (PHBV) and seeded with ASCs have been shown to withstand forces of contraction in vivo and enhance the granulation, re-epithelialization, and vascularization of wounded skin, resulting in skin with a well-organized dermal matrix with sebaceous glands and hair follicles and less scarring after 28 days [166].

Computational modeling of cell behavior and the biophysical processes within the healing tissue can inform the design of efficient scaffolds sensitive to these complex processes, to promote a regenerative wound healing environment. Processes such as the changes in fluid composition, mechanical stress, cell density, and nutrient levels, for example, can be modeled, to create scaffolds timely release of molecules, efficient cell spreading, transport and consumption of nutrients, and controlled scaffold degradation [149]. Despite advances in the development of biomedical dressings and current insights into skin healing, more comprehensive models specifically conceived for skin regeneration are yet to be devised [149].

Additionally, MSCs can be differentiated or preconditioned for therapeutic potential. The differentiation of MSCs towards specific cell fates can be enhanced through the introduction of transcription factors. MSCs have successfully been differentiated into neural, pancreatic, and endothelial cells [167]. A wound environment more permissive for differentiation can also be created to maximize the performance of stem cell-based approaches. Wounded tissue is hypoxic due to the disruption of the blood vessels and increased oxygen 
consumption by the local cells [168]. Chronic wounds may be especially subject to metabolic perturbations including ischemia or hyperglycemia, which may influence MSC behavior. Hypoxic preconditioning of cultured MSCs has been found to beneficially influence MSC activity, with no effect on MSC viability [169], except if prolonged [170]. The conditioned media from ASCs cultured under hypoxic conditions, maintained in normoxic environment, increases MSC migration through matrigel [171] and on tissue culture plastic [172] by upregulating MMPs. Hypoxic culturing improves MSC proliferation, clonogenicity, survival, and engraftment [95] and accelerates wound closure [73]. Conditioned media from ASCs harvested under hypoxia promotes collagen synthesis compared with that harvested under normoxia [73]. Low oxygen-level conditions increase hypoxia-inducible factor- (HIF-) 1a synthesis, which activates a number of genes involved in angiogenesis and wound healing, including PDGF, TGF- $\beta 1$ and TGF- $\beta 3$, and SDF- 1 [173-177]. The growth factors VEGF and bFGF may be potential mediators of this increased efficacy of hypoxic conditioned media of BMSCs, ASCs, and amniotic fluid-derived MSCs $[73,178,179]$. VEGF and bFGF are proangiogenic and induce proliferation and migration of keratinocytes, human dermal fibroblasts, endothelial cells, and monocytes. Hypoxic culture results in strong secretion of immunomodulatory molecules such as programmed death ligand-1 and indoleamine 2,3-dioxygenase and modulates inflammatory cell recruitment, which positively impacts the inflammatory phase of wound healing, favoring reduced inflammation and regenerative wound healing [180].

\section{Current Limitations and Future Directions}

Despite advancements in MSC-based therapy, there are a number of challenges to overcome before MSCs can be used for effective wound healing. The heterogeneity in MSC surface receptor expression and MSC behavior within and between studies emphasizes the importance of consistent criteria to define MSCs, standardized protocols for isolation and expansion, and standard in vivo assays to demonstrate their identity prior to therapeutic administration. Most of the mechanisms discussed have been studied in rodents, but animal physiology cannot always be extrapolated to humans. The therapeutic potential of MSCs in human wounds is currently only supported by a small number of clinical studies, and, while results are promising, they are limited by small sample sizes, short follow-up periods, and lack of randomized controlled trials. There are several trials currently recruiting patients to examine the longer-term outcomes of BMSC therapy on diabetic and venous ulcers. Current understanding of MSC mechanisms is still unfolding, and further investigation into how MSC-derived signals target cells and cellular responses spatiotemporally in vivo is needed.

\section{Conclusion}

MSC-based therapy is emerging as a promising technique able to promote wound healing and minimize scarring. Their easy and convenient isolation, extensive proliferation potential and differentiation capacity, and lack of significant immunogenicity and ethical controversy make MSCs attractive therapeutic agents. MSCs promote healing in all phases of wound repair. They migrate to sites of cutaneous injury and, primarily through paracrine signaling, suppress inflammation and stimulate the proliferation and differentiation of resident progenitor cells including fibroblasts, endothelial cells, and epidermal cells. MSCs modify their activities and functions depending on the biomolecular context and exposure to biochemical factors characteristic of an injury environment such as hypoxia. Current challenges with the use of MSCs concern the lack of universally accepted criteria for defining the MSC phenotype or their functional properties, and further clinical trials are needed to demonstrate the therapeutic potential of MSCs in a larger number of patients.

\section{Conflicts of Interest}

The authors declare that there is no conflict of interest regarding the publication of this paper.

\section{References}

[1] P. Martin, "Wound healing-aiming for perfect skin regeneration," Science, vol. 276, no. 5309, pp. 75-81, 1997.

[2] A. J. Singer and R. A. F. Clark, "Cutaneous wound healing," New England Journal of Medicine, vol. 341, no. 10, pp. 738746, 1999.

[3] M. S. Hu, Z. N. Maan, J.-C. Wu et al., "Tissue engineering and regenerative repair in wound healing," Annals of Biomedical Engineering, vol. 42, no. 7, pp. 1494-1507, 2014.

[4] C. Pang, A. Ibrahim, N. W. Bulstrode, and P. Ferretti, “An overview of the therapeutic potential of regenerative medicine in cutaneous wound healing," International Wound Journal, vol. 14, no. 3, pp. 450-459, 2017.

[5] R. A. F. Clark, "Wound repair. Overview and general considerations," in The Molecular and Cellular Biology of Wound Repair, Springer, Boston, MA, USA, 1994.

[6] L. Vileikyte, "Diabetic foot ulcers: a quality of life issue," Diabetes/Metabolism Research and Reviews, vol. 17, no. 4, pp. 246-249, 2001.

[7] S. E. Hanson, M. L. Bentz, and P. Hematti, "Mesenchymal stem cell therapy for nonhealing cutaneous wounds," Plastic and Reconstructive Surgery, vol. 125, no. 2, pp. 510-516, 2010.

[8] C. K. Sen, G. M. Gordillo, S. Roy et al., "Human skin wounds: a major and snowballing threat to public health and the economy," Wound Repair and Regeneration, vol. 17, no. 6, pp. 763-771, 2009.

[9] T. Velnar, T. Bailey, and V. Smrkolj, "The wound healing process: an overview of the cellular and molecular mechanisms," Journal of International Medical Research, vol. 37, no. 5, pp. 1528-1542, 2009.

[10] T. A. Mustoe, K. O’Shaughnessy, and O. Kloeters, “Chronic wound pathogenesis and current treatment strategies: a unifying hypothesis," Plastic and Reconstructive Surgery, vol. 117, no. 7S, pp. 35S-41S, 2006. 
[11] Y. Yamaguchi and K. Yoshikawa, "Cutaneous wound healing: an update," The Journal of Dermatology, vol. 28, no. 10, pp. 521-534, 2001.

[12] A. J. Friedenstein, R. K. Chailakhjan, and K. S. Lalykina, “The development of fibroblast colonies in monolayer cultures of guinea-pig bone marrow and spleen cells," Cell Proliferation, vol. 3, no. 4, pp. 393-403, 1970.

[13] M. F. Pittenger, A. M. Mackay, S. C. Beck et al., "Multilineage potential of adult human mesenchymal stem cells," Science, vol. 284, no. 5411, pp. 143-147, 1999.

[14] A. Dicker, K. le Blanc, G. Åström et al., "Functional studies of mesenchymal stem cells derived from adult human adipose tissue," Experimental Cell Research, vol. 308, no. 2, pp. 283-290, 2005.

[15] P. A. Zuk, M. Zhu, H. Mizuno et al., "Multilineage cells from human adipose tissue: implications for cell-based therapies," Tissue Engineering, vol. 7, no. 2, pp. 211-228, 2001.

[16] G. D. Richardson, E. C. Arnott, C. Jenna Whitehouse, C. M. Lawrence, N. Hole, and C. A. B. Jahoda, "Cultured cells from the adult human hair follicle dermis can be directed toward adipogenic and osteogenic differentiation," The Journal of Investigative Dermatology, vol. 124, no. 5, pp. 1090-1091, 2005.

[17] T. Miki, K. Mitamura, M. A. Ross, D. B. Stolz, and S. C. Strom, "Identification of stem cell marker-positive cells by immunofluorescence in term human amnion," Journal of Reproductive Immunology, vol. 75, no. 2, pp. 91-96, 2007.

[18] K. Kita, G. G. Gauglitz, T. T. Phan, D. N. Herndon, and M. G. Jeschke, "Isolation and characterization of mesenchymal stem cells from the sub-amniotic human umbilical cord lining membrane," Stem Cells and Development, vol. 19, no. 4, pp. 491-502, 2010.

[19] H. S. Wang, S. C. Hung, S. T. Peng et al., "Mesenchymal stem cells in the Wharton's jelly of the human umbilical cord," Stem Cells, vol. 22, no. 7, pp. 1330-1337, 2004.

[20] Y. A. Romanov, V. A. Svintsitskaya, and V. N. Smirnov, "Searching for alternative sources of postnatal human mesenchymal stem cells: candidate MSC-like cells from umbilical cord," Stem Cells, vol. 21, no. 1, pp. 105-110, 2003.

[21] D. Baksh, R. Yao, and R. S. Tuan, "Comparison of proliferative and multilineage differentiation potential of human mesenchymal stem cells derived from umbilical cord and bone marrow," Stem Cells, vol. 25, no. 6, pp. 1384-1392, 2007.

[22] O. K. Lee, T. K. Kuo, W.-M. Chen, K.-D. Lee, S.-L. Hsieh, and T.-H. Chen, "Isolation of multipotent mesenchymal stem cells from umbilical cord blood," Blood, vol. 103, no. 5, pp. 1669-1675, 2004.

[23] X. Zhang, M. Hirai, S. Cantero et al., "Isolation and characterization of mesenchymal stem cells from human umbilical cord blood: reevaluation of critical factors for successful isolation and high ability to proliferate and differentiate to chondrocytes as compared to mesenchymal stem cells from bone marrow and adipose tissue," Journal of Cellular Biochemistry, vol. 112, no. 4, pp. 1206-1218, 2011.

[24] D. L. Troyer and M. L. Weiss, "Concise review: Wharton's jelly-derived cells are a primitive stromal cell population," Stem Cells, vol. 26, no. 3, pp. 591-599, 2008.

[25] A. I. Caplan, "Mesenchymal stem cells," Journal of Orthopaedic Research, vol. 9, no. 5, pp. 641-650, 1991.
[26] P. Bianco, P. G. Robey, and P. J. Simmons, "Mesenchymal stem cells: revisiting history, concepts, and assays," Cell Stem Cell, vol. 2, no. 4, pp. 313-319, 2008.

[27] E. Horwitz, K. le Blanc, M. Dominici et al., "Clarification of the nomenclature for MSC: the International Society for Cellular Therapy position statement," Cytotherapy, vol. 7, no. 5, pp. 393-395, 2005.

[28] M. Dominici, P. Paolucci, P. Conte, and E. M. Horwitz, "Heterogeneity of multipotent mesenchymal stromal cells: from stromal cells to stem cells and vice versa," Transplantation, vol. 87, no. 9S, pp. S36-S42, 2009.

[29] P. Charbord, E. Livne, G. Gross et al., "Human bone marrow mesenchymal stem cells: a systematic reappraisal via the genostem experience," Stem Cell Reviews and Reports, vol. 7, no. 1, pp. 32-42, 2011.

[30] A. Keating, "Mesenchymal stromal cells," Current Opinion in Hematology, vol. 13, no. 6, pp. 419-425, 2006.

[31] A. P. Beltrami, D. Cesselli, N. Bergamin et al., "Multipotent cells can be generated in vitro from several adult human organs (heart, liver, and bone marrow)," Blood, vol. 110, no. 9, pp. 3438-3446, 2007.

[32] Y. Jiang, B. Vaessen, T. Lenvik, M. Blackstad, M. Reyes, and C. M. Verfaillie, "Multipotent progenitor cells can be isolated from postnatal murine bone marrow, muscle, and brain," Experimental Hematology, vol. 30, no. 8, pp. 896-904, 2002.

[33] B. C. Heng, T. Cao, H. Liu, and T. T. Phan, "Directing stem cells into the keratinocyte lineage in vitro," Experimental Dermatology, vol. 14, no. 1, pp. 1-16, 2005.

[34] K. M. Safford, K. C. Hicok, S. D. Safford et al., "Neurogenic differentiation of murine and human adipose-derived stromal cells," Biochemical and Biophysical Research Communications, vol. 294, no. 2, pp. 371-379, 2002.

[35] P. Bianco, "Life in plastic is fantastic," Blood, vol. 110, no. 9, p. 3090, 2007.

[36] A. J. Wagers and I. L. Weissman, "Plasticity of adult stem cells," Cell, vol. 116, no. 5, pp. 639-648, 2004.

[37] G. Vassilopoulos and D. W. Russell, "Cell fusion: an alternative to stem cell plasticity and its therapeutic implications," Current Opinion in Genetics \& Development, vol. 13, no. 5, pp. 480-485, 2003.

[38] A. Peister, J. A. Mellad, B. L. Larson, B. M. Hall, L. F. Gibson, and D. J. Prockop, "Adult stem cells from bone marrow (MSCs) isolated from different strains of inbred mice vary in surface epitopes, rates of proliferation, and differentiation potential," Blood, vol. 103, no. 5, pp. 1662-1668, 2004.

[39] W. Wagner, R. E. Feldmann Jr, A. Seckinger et al., "The heterogeneity of human mesenchymal stem cell preparation$\mathrm{s}$-evidence from simultaneous analysis of proteomes and transcriptomes," Experimental Hematology, vol. 34, no. 4, pp. 536-548, 2006.

[40] M. Dominici, K. le Blanc, I. Mueller et al., "Minimal criteria for defining multipotent mesenchymal stromal cells. The International Society for Cellular Therapy position statement," Cytotherapy, vol. 8, no. 4, pp. 315-317, 2006.

[41] M. Crisan, S. Yap, L. Casteilla et al., "A perivascular origin for mesenchymal stem cells in multiple human organs," Cell Stem Cell, vol. 3, no. 3, pp. 301-313, 2008.

[42] L. da Silva Meirelles, A. I. Caplan, and N. B. Nardi, "In search of the in vivo identity of mesenchymal stem cells," Stem Cells, vol. 26, no. 9, pp. 2287-2299, 2008. 
[43] B. Sacchetti, A. Funari, S. Michienzi et al., "Self-renewing osteoprogenitors in bone marrow sinusoids can organize a hematopoietic microenvironment," Cell, vol. 131, no. 2, pp. 324-336, 2007.

[44] A. I. Caplan, "All MSCs are pericytes?," Cell Stem Cell, vol. 3, no. 3, pp. 229-230, 2008.

[45] W. Rahmani, S. Abbasi, A. Hagner et al., "Hair follicle dermal stem cells regenerate the dermal sheath, repopulate the dermal papilla, and modulate hair type," Developmental Cell, vol. 31, no. 5, pp. 543-558, 2014.

[46] K. Sellheyer and D. Krahl, "Skin mesenchymal stem cells: prospects for clinical dermatology," Journal of the American Academy of Dermatology, vol. 63, no. 5, pp. 859-865, 2010.

[47] C. A. B. Jahoda and A. J. Reynolds, "Hair follicle dermal sheath cells: unsung participants in wound healing," The Lancet, vol. 358, no. 9291, pp. 1445-1448, 2001.

[48] J. G. Toma, I. A. McKenzie, D. Bagli, and F. D. Miller, "Isolation and characterization of multipotent skin-derived precursors from human skin," Stem Cells, vol. 23, no. 6, pp. 727737, 2005.

[49] R. F. Oliver, "Whisker growth after removal of the dermal papilla and lengths of follicle in the hooded rat," Development, vol. 15, no. 3, pp. 331-347, 1966.

[50] R. J. Bodnar, L. Satish, C. C. Yates, and A. Wells, "Pericytes: a newly recognized player in wound healing," Wound Repair and Regeneration, vol. 24, no. 2, pp. 204-214, 2016.

[51] S. Paquet-Fifield, H. Schlüter, A. Li et al., "A role for pericytes as microenvironmental regulators of human skin tissue regeneration," The Journal of Clinical Investigation, vol. 119, no. 9, pp. 2795-2806, 2009.

[52] B. A. Schmidt and V. Horsley, "Intradermal adipocytes mediate fibroblast recruitment during skin wound healing," Development, vol. 140, no. 7, pp. 1517-1527, 2013.

[53] Y. Wang, Y. Sun, X. Y. Yang, S. Z. Ji, S. Han, and Z. F. Xia, "Mobilised bone marrow-derived cells accelerate wound healing," International Wound Journal, vol. 10, no. 4, pp. 473-479, 2013.

[54] S. R. Opalenik and J. M. Davidson, "Fibroblast differentiation of bone marrow-derived cells during wound repair," The FASEB Journal, vol. 19, no. 11, pp. 1561-1563, 2005.

[55] E. Seppanen, E. Roy, R. Ellis, G. Bou-Gharios, N. M. Fisk, and K. Khosrotehrani, "Distant mesenchymal progenitors contribute to skin wound healing and produce collagen: evidence from a murine fetal microchimerism model," PLoS One, vol. 8, no. 5, article e62662, 2013.

[56] C. Fathke, L. Wilson, J. Hutter et al., "Contribution of bone marrow-derived cells to skin: collagen deposition and wound repair," Stem Cells, vol. 22, no. 5, pp. 812-822, 2004.

[57] E. V. Badiavas and V. Falanga, "Treatment of chronic wounds with bone marrow-derived cells," Archives of Dermatology, vol. 139, no. 4, pp. 510-516, 2003.

[58] V. Falanga, S. Iwamoto, M. Chartier et al., "Autologous bone marrow-derived cultured mesenchymal stem cells delivered in a fibrin spray accelerate healing in murine and human cutaneous wounds," Tissue Engineering, vol. 13, no. 6, pp. 1299-1312, 2007.

[59] T. Yoshikawa, H. Mitsuno, I. Nonaka et al., "Wound therapy by marrow mesenchymal cell transplantation," Plastic and Reconstructive Surgery, vol. 121, no. 3, pp. 860-877, 2008.

[60] N. R. Dash, S. N. Dash, P. Routray, S. Mohapatra, and P. C. Mohapatra, "Targeting nonhealing ulcers of lower extremity in human through autologous bone marrow-derived mesenchymal stem cells," Rejuvenation Research, vol. 12, no. 5, pp. 359-366, 2009.

[61] D. Lu, B. Chen, Z. Liang et al., "Comparison of bone marrow mesenchymal stem cells with bone marrow-derived mononuclear cells for treatment of diabetic critical limb ischemia and foot ulcer: a double-blind, randomized, controlled trial," Diabetes Research and Clinical Practice, vol. 92, no. 1, pp. 26-36, 2011.

[62] M. S. Rao and M. P. Mattson, "Stem cells and aging: expanding the possibilities," Mechanisms of Ageing and Development, vol. 122, no. 7, pp. 713-734, 2001.

[63] F. P. Barry and J. M. Murphy, "Mesenchymal stem cells: clinical applications and biological characterization," The International Journal of Biochemistry \& Cell Biology, vol. 36, no. 4, pp. 568-584, 2004.

[64] S. Böttcher-Haberzeth, T. Biedermann, A. S. Klar et al., "Tissue engineering of skin: human tonsil-derived mesenchymal cells can function as dermal fibroblasts," Pediatric Surgery International, vol. 30, no. 2, pp. 213-222, 2014.

[65] F. Lu, J. Li, J. Gao et al., "Improvement of the survival of human autologous fat transplantation by using VEGFtransfected adipose-derived stem cells," Plastic and Reconstructive Surgery, vol. 124, no. 5, pp. 1437-1446, 2009.

[66] B. Puissant, C. Barreau, P. Bourin et al., "Immunomodulatory effect of human adipose tissue-derived adult stem cells: comparison with bone marrow mesenchymal stem cells," British Journal of Haematology, vol. 129, no. 1, pp. 118-129, 2005.

[67] D. Ma, J. E. H. Kua, W. K. Lim, S. T. Lee, and A. W. C. Chua, "In vitro characterization of human hair follicle dermal sheath mesenchymal stromal cells and their potential in enhancing diabetic wound healing," Cytotherapy, vol. 17, no. 8, pp. 1036-1051, 2015.

[68] R. R. Driskell, C. Clavel, M. Rendl, and F. M. Watt, "Hair follicle dermal papilla cells at a glance," Journal of Cell Science, vol. 124, no. 8, pp. 1179-1182, 2011.

[69] S. T.-F. Hsiao, A. Asgari, Z. Lokmic et al., "Comparative analysis of paracrine factor expression in human adult mesenchymal stem cells derived from bone marrow, adipose, and dermal tissue," Stem Cells and Development, vol. 21, no. 12, pp. 2189-2203, 2012.

[70] S. S. Collawn, N. S. Banerjee, J. de la Torre, L. Vasconez, and L. T. Chow, "Adipose-derived stromal cells accelerate wound healing in an organotypic raft culture model," Annals of Plastic Surgery, vol. 68, no. 5, pp. 501-504, 2012.

[71] S. H. Lee, S. Y. Jin, J. S. Song, K. K. Seo, and K. H. Cho, "Paracrine effects of adipose-derived stem cells on keratinocytes and dermal fibroblasts," Annals of Dermatology, vol. 24, no. 2, pp. 136-143, 2012.

[72] Y. Kato, T. Iwata, K. Washio et al., "Creation and transplantation of an adipose-derived stem cell (ASC) sheet in a diabetic wound-healing model," Journal of Visualized Experiments, no. 126, 2017.

[73] E. Y. Lee, Y. Xia, W. S. Kim et al., "Hypoxia-enhanced wound-healing function of adipose-derived stem cells: increase in stem cell proliferation and up-regulation of VEGF and bFGF," Wound Repair and Regeneration, vol. 17, no. 4, pp. 540-547, 2009.

[74] M. Nambu, S. Kishimoto, S. Nakamura et al., "Accelerated wound healing in healing-impaired $d b / d b$ mice by autologous adipose tissue-derived stromal cells combined with 
atelocollagen matrix," Annals of Plastic Surgery, vol. 62, no. 3, pp. 317-321, 2009.

[75] C. Nie, D. Yang, J. Xu, Z. Si, X. Jin, and J. Zhang, "Locally administered adipose-derived stem cells accelerate wound healing through differentiation and vasculogenesis," Cell Transplantation, vol. 20, no. 2, pp. 205-216, 2011.

[76] F. Lu, H. Mizuno, C. A. Uysal, X. Cai, R. Ogawa, and H. Hyakusoku, "Improved viability of random pattern skin flaps through the use of adipose-derived stem cells," Plastic and Reconstructive Surgery, vol. 121, no. 1, pp. 50-58, 2008.

[77] S. Akita, K. Akino, A. Hirano, A. Ohtsuru, and S. Yamashita, "Noncultured autologous adipose-derived stem cells therapy for chronic radiation injury," Stem Cells International, vol. 2010, Article ID 532704, 8 pages, 2010.

[78] M. A. Boink, L. J. van den Broek, S. Roffel et al., "Different wound healing properties of dermis, adipose, and gingiva mesenchymal stromal cells," Wound Repair and Regeneration, vol. 24, no. 1, pp. 100-109, 2016.

[79] F. Jiménez, C. Garde, E. Poblet et al., "A pilot clinical study of hair grafting in chronic leg ulcers," Wound Repair and Regeneration, vol. 20, no. 6, pp. 806-814, 2012.

[80] M.-L. Martínez, E. Escario, E. Poblet et al., "Hair follicle-containing punch grafts accelerate chronic ulcer healing: a randomized controlled trial," Journal of the American Academy of Dermatology, vol. 75, no. 5, pp. 1007-1014, 2016.

[81] S. Maxson, E. A. Lopez, D. Yoo, A. Danilkovitch-Miagkova, and M. A. LeRoux, "Concise review: role of mesenchymal stem cells in wound repair," Stem Cells Translational Medicine, vol. 1, no. 2, pp. 142-149, 2012.

[82] J. Cha and V. Falanga, "Stem cells in cutaneous wound healing," Clinics in Dermatology, vol. 25, no. 1, pp. 73-78, 2007.

[83] S. M. Millard and N. M. Fisk, "Mesenchymal stem cells for systemic therapy: shotgun approach or magic bullets?," BioEssays, vol. 35, no. 3, pp. 173-182, 2013.

[84] J. E. Janis and B. Harrison, "Wound healing: part I. Basic science," Plastic and Reconstructive Surgery, vol. 133, no. 2, pp. 199e-207e, 2014.

[85] N. Takagi, K. Kawakami, E. Kanno et al., "IL-17A promotes neutrophilic inflammation and disturbs acute wound healing in skin," Experimental Dermatology, vol. 26, no. 2, pp. 137-144, 2017.

[86] T. E. Serena, B. M. Cullen, S. W. Bayliff et al., "Defining a new diagnostic assessment parameter for wound care: elevated protease activity, an indicator of nonhealing, for targeted protease-modulating treatment," Wound Repair and Regeneration, vol. 24, no. 3, pp. 589-595, 2016.

[87] J. M. Rhett, G. S. Ghatnekar, J. A. Palatinus, M. O'Quinn, M. J. Yost, and R. G. Gourdie, "Novel therapies for scar reduction and regenerative healing of skin wounds," Trends in Biotechnology, vol. 26, no. 4, pp. 173-180, 2008.

[88] R. Mirza, L. A. DiPietro, and T. J. Koh, "Selective and specific macrophage ablation is detrimental to wound healing in mice," The American Journal of Pathology, vol. 175, no. 6, pp. 2454-2462, 2009.

[89] A. L. Brubaker, J. L. Rendon, L. Ramirez, M. A. Choudhry, and E. J. Kovacs, "Reduced neutrophil chemotaxis and infiltration contributes to delayed resolution of cutaneous wound infection with advanced age," The Journal of Immunology, vol. 190, no. 4, pp. 1746-1757, 2013.
[90] G. Ishii, T. Sangai, K. Sugiyama et al., "In vivo characterization of bone marrow-derived fibroblasts recruited into fibrotic lesions," Stem Cells, vol. 23, no. 5, pp. 699-706, 2005.

[91] Y. Mishima and M. Lotz, "Chemotaxis of human articular chondrocytes and mesenchymal stem cells," Journal of Orthopaedic Research, vol. 26, no. 10, pp. 1407-1412, 2008.

[92] H. Hemeda, M. Jakob, A.-K. Ludwig, B. Giebel, S. Lang, and S. Brandau, "Interferon- $\gamma$ and tumor necrosis factor- $\alpha$ differentially affect cytokine expression and migration properties of mesenchymal stem cells," Stem Cells and Development, vol. 19, no. 5, pp. 693-706, 2010.

[93] A. L. Ponte, E. Marais, N. Gallay et al., "The in vitro migration capacity of human bone marrow mesenchymal stem cells: comparison of chemokine and growth factor chemotactic activities," Stem Cells, vol. 25, no. 7, pp. 1737-1745, 2007.

[94] M. Sasaki, R. Abe, Y. Fujita, S. Ando, D. Inokuma, and H. Shimizu, "Mesenchymal stem cells are recruited into wounded skin and contribute to wound repair by transdifferentiation into multiple skin cell type," The Journal of Immunology, vol. 180, no. 4, pp. 2581-2587, 2008.

[95] J. M. Karp and G. S. Leng Teo, "Mesenchymal stem cell homing: the devil is in the details," Cell Stem Cell, vol. 4, no. 3, pp. 206-216, 2009.

[96] L. Liu, Y. Yu, Y. Hou et al., "Human umbilical cord mesenchymal stem cells transplantation promotes cutaneous wound healing of severe burned rats," PLoS One, vol. 9, no. 2, article e88348, 2014.

[97] A. Bartholomew, C. Sturgeon, M. Siatskas et al., "Mesenchymal stem cells suppress lymphocyte proliferation in vitro and prolong skin graft survival in vivo," Experimental Hematology, vol. 30, no. 1, pp. 42-48, 2002.

[98] M. Di Nicola, C. Carlo-Stella, M. Magni et al., "Human bone marrow stromal cells suppress T-lymphocyte proliferation induced by cellular or nonspecific mitogenic stimuli," Blood, vol. 99, no. 10, pp. 3838-3843, 2002.

[99] G. Ren, L. Zhang, X. Zhao et al., "Mesenchymal stem cellmediated immunosuppression occurs via concerted action of chemokines and nitric oxide," Cell Stem Cell, vol. 2, no. 2, pp. 141-150, 2008.

[100] A. Corcione, F. Benvenuto, E. Ferretti et al., "Human mesenchymal stem cells modulate B-cell functions," Blood, vol. 107, no. 1, pp. 367-372, 2006.

[101] P. A. Sotiropoulou, S. A. Perez, A. D. Gritzapis, C. N. Baxevanis, and M. Papamichail, "Interactions between human mesenchymal stem cells and natural killer cells," Stem Cells, vol. 24, no. 1, pp. 74-85, 2006.

[102] S. Aggarwal and M. F. Pittenger, "Human mesenchymal stem cells modulate allogeneic immune cell responses," Blood, vol. 105, no. 4, pp. 1815-1822, 2005.

[103] A. E. Aksu, E. Horibe, J. Sacks et al., "Co-infusion of donor bone marrow with host mesenchymal stem cells treats GVHD and promotes vascularized skin allograft survival in rats," Clinical Immunology, vol. 127, no. 3, pp. 348-358, 2008.

[104] L. Chiossone, R. Conte, G. M. Spaggiari et al., "Mesenchymal stromal cells induce peculiar alternatively activated macrophages capable of dampening both innate and adaptive immune responses," Stem Cells, vol. 34, no. 7, pp. 19091921, 2016.

[105] P.-M. Chen, K.-J. Liu, P.-J. Hsu et al., "Induction of immunomodulatory monocytes by human mesenchymal stem cell- 
derived hepatocyte growth factor through ERK1/2," Journal of Leukocyte Biology, vol. 96, no. 2, pp. 295-303, 2014.

[106] K. Németh, A. Leelahavanichkul, P. S. T. Yuen et al., "Bone marrow stromal cells attenuate sepsis via prostaglandin $\mathrm{E}_{2}-$ dependent reprogramming of host macrophages to increase their interleukin-10 production," Nature Medicine, vol. 15, no. 1, pp. 42-49, 2009.

[107] D.-I. Cho, M. R. Kim, H. Y. Jeong et al., "Mesenchymal stem cells reciprocally regulate the M1/M2 balance in mouse bone marrow-derived macrophages," Experimental \& Molecular Medicine, vol. 46, no. 1, article e70, 2014.

[108] S. M. Melief, E. Schrama, M. H. Brugman et al., "Multipotent stromal cells induce human regulatory $\mathrm{T}$ cells through a novel pathway involving skewing of monocytes toward antiinflammatory macrophages," Stem Cells, vol. 31, no. 9, pp. 1980-1991, 2013.

[109] J. Kim and P. Hematti, "Mesenchymal stem cell-educated macrophages: a novel type of alternatively activated macrophages," Experimental Hematology, vol. 37, no. 12, pp. 1445-1453, 2009.

[110] J. Y. Oh, J. H. Ko, H. J. Lee et al., "Mesenchymal stem/stromal cells inhibit the NLRP3 inflammasome by decreasing mitochondrial reactive oxygen species," Stem Cells, vol. 32, no. 6, pp. 1553-1563, 2014.

[111] C.-P. Chen, Y.-Y. Chen, J.-P. Huang, and Y.-H. Wu, "The effect of conditioned medium derived from human placental multipotent mesenchymal stromal cells on neutrophils: possible implications for placental infection," MHR: Basic Science of Reproductive Medicine, vol. 20, no. 11, pp. 11171125, 2014.

[112] S. C. Wu, W. Marston, and D. G. Armstrong, "Wound care: the role of advanced wound healing technologies," Journal of Vascular Surgery, vol. 52, no. 3, pp. 59S-66S, 2010.

[113] J. Maggini, G. Mirkin, I. Bognanni et al., "Mouse bone marrow-derived mesenchymal stromal cells turn activated macrophages into a regulatory-like profile," PLoS One, vol. 5, no. 2, article e9252, 2010.

[114] H. Ohtaki, J. H. Ylostalo, J. E. Foraker et al., "Stem/progenitor cells from bone marrow decrease neuronal death in global ischemia by modulation of inflammatory/immune responses," Proceedings of the National Academy of Sciences, vol. 105, no. 38, pp. 14638-14643, 2008.

[115] A. Krasnodembskaya, Y. Song, X. Fang et al., “Antibacterial effect of human mesenchymal stem cells is mediated in part from secretion of the antimicrobial peptide LL-37," Stem Cells, vol. 28, no. 12, pp. 2229-2238, 2010.

[116] J. M. Reinke and H. Sorg, "Wound repair and regeneration," European Surgical Research, vol. 49, no. 1, pp. 35-43, 2012.

[117] J. Li, J. Chen, and R. Kirsner, "Pathophysiology of acute wound healing," Clinics in Dermatology, vol. 25, no. 1, pp. 9-18, 2007.

[118] N. X. Landén, D. Li, and M. Ståhle, "Transition from inflammation to proliferation: a critical step during wound healing," Cellular and Molecular Life Sciences, vol. 73, no. 20, pp. 38613885, 2016.

[119] K. McFarlin, X. Gao, Y. B. Liu et al., "Bone marrow-derived mesenchymal stromal cells accelerate wound healing in the rat," Wound Repair and Regeneration, vol. 14, no. 4, pp. 471-478, 2006.

[120] E. H. Javazon, S. G. Keswani, A. T. Badillo et al., "Enhanced epithelial gap closure and increased angiogenesis in wounds of diabetic mice treated with adult murine bone marrow stromal progenitor cells," Wound Repair and Regeneration, vol. 15, no. 3, pp. 350-359, 2007.

[121] Y. Wu, L. Chen, P. G. Scott, and E. E. Tredget, "Mesenchymal stem cells enhance wound healing through differentiation and angiogenesis," Stem Cells, vol. 25, no. 10, pp. 26482659, 2007.

[122] M. P. Alfaro, M. Pagni, A. Vincent et al., "The Wnt modulator sFRP2 enhances mesenchymal stem cell engraftment, granulation tissue formation and myocardial repair," Proceedings of the National Academy of Sciences, vol. 105, no. 47, pp. 18366-18371, 2008.

[123] H. Li, X. Fu, Y. Ouyang, C. Cai, J. Wang, and T. Sun, “Adult bone-marrow-derived mesenchymal stem cells contribute to wound healing of skin appendages," Cell and Tissue Research, vol. 326, no. 3, pp. 725-736, 2006.

[124] C. A. Uysal, M. Tobita, H. Hyakusoku, and H. Mizuno, "The effect of bone-marrow-derived stem cells and adiposederived stem cells on wound contraction and epithelization," Advances in Wound Care, vol. 3, no. 6, pp. 405-413, 2014.

[125] W.-S. Kim, B.-S. Park, J.-H. Sung et al., "Wound healing effect of adipose-derived stem cells: a critical role of secretory factors on human dermal fibroblasts," Journal of Dermatological Science, vol. 48, no. 1, pp. 15-24, 2007.

[126] K. C. Rustad, V. W. Wong, M. Sorkin et al., "Enhancement of mesenchymal stem cell angiogenic capacity and stemness by a biomimetic hydrogel scaffold," Biomaterials, vol. 33, no. 1, pp. 80-90, 2012.

[127] W. Deng, Q. Han, L. Liao et al., "Engrafted bone marrowderived Flk $1^{+}$mesenchymal stem cells regenerate skin tissue," Tissue Engineering, vol. 11, no. 1-2, pp. 110-119, 2005.

[128] A. M. Hocking and N. S. Gibran, "Mesenchymal stem cells: paracrine signaling and differentiation during cutaneous wound repair," Experimental Cell Research, vol. 316, no. 14, pp. 2213-2219, 2010.

[129] L. Chen, E. E. Tredget, P. Y. G. Wu, and Y. Wu, "Paracrine factors of mesenchymal stem cells recruit macrophages and endothelial lineage cells and enhance wound healing," PLoS One, vol. 3, no. 4, article e1886, 2008.

[130] B. S. Park, K. A. Jang, J. H. Sung et al., "Adipose-derived stem cells and their secretory factors as a promising therapy for skin aging," Dermatologic Surgery, vol. 34, no. 10, pp. 13231326, 2008.

[131] J. Rehman, D. Traktuev, J. Li et al., "Secretion of angiogenic and antiapoptotic factors by human adipose stromal cells," Circulation, vol. 109, no. 10, pp. 1292-1298, 2004.

[132] J. P. Miranda, E. Filipe, A. S. Fernandes et al., "The human umbilical cord tissue-derived MSC population UCX ${ }^{\circledast}$ promotes early motogenic effects on keratinocytes and fibroblasts and G-CSF-mediated mobilization of BM-MSCs when transplanted in vivo," Cell Transplantation, vol. 24, no. 5, pp. 865-877, 2015.

[133] M. H. Moon, S. Y. Kim, Y. J. Kim et al., "Human adipose tissue-derived mesenchymal stem cells improve postnatal neovascularization in a mouse model of hindlimb ischemia," Cellular Physiology and Biochemistry, vol. 17, no. 5-6, pp. 279-290, 2006.

[134] A. N. Smith, E. Willis, V. T. Chan et al., "Mesenchymal stem cells induce dermal fibroblast responses to injury," Experimental Cell Research, vol. 316, no. 1, pp. 48-54, 2010. 
[135] S.-W. Kim, H.-Z. Zhang, L. Guo, J.-M. Kim, and M. H. Kim, "Amniotic mesenchymal stem cells enhance wound healing in diabetic NOD/SCID mice through high angiogenic and engraftment capabilities," PLoS One, vol. 7, no. 7, article e41105, 2012.

[136] B. S. Yoon, J.-H. Moon, E. K. Jun et al., "Secretory profiles and wound healing effects of human amniotic fluid-derived mesenchymal stem cells," Stem Cells and Development, vol. 19, no. 6, pp. 887-902, 2010.

[137] R. Montesano and L. Orci, "Transforming growth factor beta stimulates collagen-matrix contraction by fibroblasts: implications for wound healing," Proceedings of the National Academy of Sciences, vol. 85, no. 13, pp. 4894-4897, 1988.

[138] R. A. Clark, J. M. Folkvord, C. E. Hart, M. J. Murray, and J. M. McPherson, "Platelet isoforms of platelet-derived growth factor stimulate fibroblasts to contract collagen matrices," Journal of Clinical Investigation, vol. 84, no. 3, pp. 10361040, 1989.

[139] M. Xue and C. J. Jackson, "Extracellular matrix reorganization during wound healing and its impact on abnormal scarring," Advances in Wound Care, vol. 4, no. 3, pp. 119136, 2015.

[140] A. Stoff, A. A. Rivera, N. Sanjib Banerjee et al., "Promotion of incisional wound repair by human mesenchymal stem cell transplantation," Experimental Dermatology, vol. 18, no. 4, pp. 362-369, 2009.

[141] D. S. Kwon, X. Gao, Y. B. Liu et al., "Treatment with bone marrow-derived stromal cells accelerates wound healing in diabetic rats," International Wound Journal, vol. 5, no. 3, pp. 453-463, 2008.

[142] S. A. Villalta, C. Rinaldi, B. Deng, G. Liu, B. Fedor, and J. G. Tidball, "Interleukin-10 reduces the pathology of $m d x$ muscular dystrophy by deactivating M1 macrophages and modulating macrophage phenotype," Human Molecular Genetics, vol. 20, no. 4, pp. 790-805, 2011.

[143] I. Ono, T. Yamashita, T. Hida et al., "Combined administration of basic fibroblast growth factor protein and the hepatocyte growth factor gene enhances the regeneration of dermis in acute incisional wounds," Wound Repair and Regeneration, vol. 12, no. 1, pp. 67-79, 2004.

[144] A. S. Colwell, S. R. Beanes, C. Soo et al., "Increased angiogenesis and expression of vascular endothelial growth factor during scarless repair," Plastic and Reconstructive Surgery, vol. 115, no. 1, pp. 204-212, 2005.

[145] M. Shah, D. M. Foreman, and M. W. Ferguson, "Neutralisation of TGF-beta 1 and TGF-beta 2 or exogenous addition of TGF-beta 3 to cutaneous rat wounds reduces scarring," Journal of Cell Science, vol. 108, no. 3, pp. 985-1002, 1995.

[146] L. Du, R. Lv, X. Yang, S. Cheng, T. Ma, and J. Xu, "Hypoxic conditioned medium of placenta-derived mesenchymal stem cells protects against scar formation," Life Sciences, vol. 149, pp. 51-57, 2016.

[147] M. T. Longaker, D. J. Whitby, N. S. Adzick et al., "Studies in fetal wound healing VI. Second and early third trimester fetal wounds demonstrate rapid collagen deposition without scar formation," Journal of Pediatric Surgery, vol. 25, no. 1, pp. 63-69, 1990.

[148] E. V. Badiavas, M. Abedi, J. Butmarc, V. Falanga, and P. Quesenberry, "Participation of bone marrow derived cells in cutaneous wound healing," Journal of Cellular Physiology, vol. 196, no. 2, pp. 245-250, 2003.
[149] D. Tartarini and E. Mele, "Adult stem cell therapies for wound healing: biomaterials and computational models," Frontiers in Bioengineering and Biotechnology, vol. 3, p. 206, 2016.

[150] W. U. Hassan, U. Greiser, and W. Wang, "Role of adiposederived stem cells in wound healing," Wound Repair and Regeneration, vol. 22, no. 3, pp. 313-325, 2014.

[151] C. Rodrigues, A. M. de Assis, D. J. Moura et al., "New therapy of skin repair combining adipose-derived mesenchymal stem cells with sodium carboxymethylcellulose scaffold in a preclinical rat model," PLoS One, vol. 9, no. 5, article e96241, 2014.

[152] D. Leonardi, D. Oberdoerfer, M. C. Fernandes et al., "Mesenchymal stem cells combined with an artificial dermal substitute improve repair in full-thickness skin wounds," Burns, vol. 38, no. 8, pp. 1143-1150, 2012.

[153] R. K. Schneider, J. Anraths, R. Kramann et al., "The role of biomaterials in the direction of mesenchymal stem cell properties and extracellular matrix remodelling in dermal tissue engineering," Biomaterials, vol. 31, no. 31, pp. 7948-7959, 2010.

[154] M. Li, Y. Zhao, H. Hao, W. Han, and X. Fu, "Mesenchymal stem cell-based therapy for nonhealing wounds: today and tomorrow," Wound Repair and Regeneration, vol. 23, no. 4, pp. 465-482, 2015.

[155] H. Ravari, D. Hamidi-Almadari, M. Salimifar, S. Bonakdaran, M. R. Parizadeh, and G. Koliakos, "Treatment of non-healing wounds with autologous bone marrow cells, platelets, fibrin glue and collagen matrix," Cytotherapy, vol. 13, no. 6, pp. 705-711, 2011.

[156] L. I. F. Moura, A. M. A. Dias, E. Carvalho, and H. C. de Sousa, "Recent advances on the development of wound dressings for diabetic foot ulcer treatment-a review," Acta Biomaterialia, vol. 9, no. 7, pp. 7093-7114, 2013.

[157] H. Nakagawa, S. Akita, M. Fukui, T. Fujii, and K. Akino, "Human mesenchymal stem cells successfully improve skinsubstitute wound healing," British Journal of Dermatology, vol. 153, no. 1, pp. 29-36, 2005.

[158] G. Chen, F. Tian, C. Li et al., "In vivo real-time visualization of mesenchymal stem cells tropism for cutaneous regeneration using NIR-II fluorescence imaging," Biomaterials, vol. 53, pp. 265-273, 2015.

[159] G. J. Leirós, A. G. Kusinsky, H. Drago et al., “Dermal papilla cells improve the wound healing process and generate hair bud-like structures in grafted skin substitutes using hair follicle stem cells," Stem Cells Translational Medicine, vol. 3, no. 10, pp. 1209-1219, 2014.

[160] K. Ma, S. Liao, L. He, J. Lu, S. Ramakrishna, and C. K. Chan, "Effects of nanofiber/stem cell composite on wound healing in acute full-thickness skin wounds," Tissue Engineering Part A, vol. 17, no. 9-10, pp. 1413-1424, 2011.

[161] J.-f. Pan, N.-h. Liu, H. Sun, and F. Xu, "Preparation and characterization of electrospun PLCL/poloxamer nanofibers and dextran/gelatin hydrogels for skin tissue engineering," PLoS One, vol. 9, no. 11, article e112885, 2014.

[162] R. Ravichandran, J. R. Venugopal, S. Sundarrajan, S. Mukherjee, J. Forsythe, and S. Ramakrishna, "Click chemistry approach for fabricating PVA/gelatin nanofibers for the differentiation of ADSCs to keratinocytes," Journal of Materials Science: Materials in Medicine, vol. 24, no. 12, pp. 2863-2871, 2013. 
[163] G. Jin, M. P. Prabhakaran, and S. Ramakrishna, "Stem cell differentiation to epidermal lineages on electrospun nanofibrous substrates for skin tissue engineering," Acta Biomaterialia, vol. 7, no. 8, pp. 3113-3122, 2011.

[164] N. Naseri, C. Algan, V. Jacobs, M. John, K. Oksman, and A. P. Mathew, "Electrospun chitosan-based nanocomposite mats reinforced with chitin nanocrystals for wound dressing," Carbohydrate Polymers, vol. 109, pp. 7-15, 2014.

[165] N. Naseri, A. P. Mathew, L. Girandon, M. Fröhlich, and K. Oksman, "Porous electrospun nanocomposite mats based on chitosan-cellulose nanocrystals for wound dressing: effect of surface characteristics of nanocrystals," Cellulose, vol. 22, no. 1, pp. 521-534, 2015.

[166] A. Zonari, T. M. M. Martins, A. C. C. Paula et al., "Polyhydroxybutyrate-co-hydroxyvalerate structures loaded with adipose stem cells promote skin healing with reduced scarring," Acta Biomaterialia, vol. 17, pp. 170-181, 2015.

[167] R. Barzilay, E. Melamed, and D. Offen, "Introducing transcription factors to multipotent mesenchymal stem cells: making transdifferentiation possible," Stem Cells, vol. 27, no. 10, pp. 2509-2515, 2009.

[168] G. M. Gordillo and C. K. Sen, "Revisiting the essential role of oxygen in wound healing," The American Journal of Surgery, vol. 186, no. 3, pp. 259-263, 2003.

[169] L. A. Mylotte, A. M. Duffy, M. Murphy et al., "Metabolic flexibility permits mesenchymal stem cell survival in an ischemic environment," Stem Cells, vol. 26, no. 5, pp. 1325-1336, 2008.

[170] E. Potier, E. Ferreira, A. Meunier, L. Sedel, D. Logeart-Avramoglou, and H. Petite, "Prolonged hypoxia concomitant with serum deprivation induces massive human mesenchymal stem cell death," Tissue Engineering, vol. 13, no. 6, pp. 1325-1331, 2007.

[171] B. Annabi, Y. T. Lee, S. Turcotte et al., "Hypoxia promotes murine bone-marrow-derived stromal cell migration and tube formation," Stem Cells, vol. 21, no. 3, pp. 337-347, 2003.

[172] I. Rosova, M. Dao, B. Capoccia, D. Link, and J. A. Nolta, "Hypoxic preconditioning results in increased motility and improved therapeutic potential of human mesenchymal stem cells," Stem Cells, vol. 26, no. 8, pp. 2173-2182, 2008.

[173] H. R. Rezvani, N. Ali, L. J. Nissen et al., "HIF-1 $\alpha$ in epidermis: oxygen sensing, cutaneous angiogenesis, cancer, and noncancer disorders," Journal of Investigative Dermatology, vol. 131, no. 9, pp. 1793-1805, 2011.

[174] G. L. Semenza, "Signal transduction to hypoxia-inducible factor 1," Biochemical Pharmacology, vol. 64, no. 5-6, pp. 993-998, 2002.

[175] M. Calvani, A. Rapisarda, B. Uranchimeg, R. H. Shoemaker, and G. Melillo, "Hypoxic induction of an HIF-1 $\alpha$-dependent bFGF autocrine loop drives angiogenesis in human endothelial cells," Blood, vol. 107, no. 7, pp. 2705-2712, 2006.

[176] H. Nishi, T. Nakada, M. Hokamura et al., "Hypoxia-inducible factor- 1 transactivates transforming growth factor- $\beta 3$ in trophoblast," Endocrinology, vol. 145, no. 9, pp. 4113-4118, 2004.

[177] S. X. L. Zhang, D. Gozal, L. R. Sachleben Jr, M. Rane, J. B. Klein, and E. Gozal, "Hypoxia induces an autocrineparacrine survival pathway via platelet-derived growth factor (PDGF)-B/PDGF- $\beta$ receptor/phosphatidylinositol 3-kinase/ Akt signaling in RN46A neuronal cells," The FASEB Journal, vol. 17, no. 12, pp. 1709-1711, 2003.
[178] T. P. Frazier, J. M. Gimble, I. Kheterpal, and B. G. Rowan, "Impact of low oxygen on the secretome of human adiposederived stromal/stem cell primary cultures," Biochimie, vol. 95, no. 12, pp. 2286-2296, 2013.

[179] L. Chen, Y. Xu, J. Zhao et al., "Conditioned medium from hypoxic bone marrow-derived mesenchymal stem cells enhances wound healing in mice," PLoS One, vol. 9, no. 4, article e96161, 2014.

[180] M. Roemeling-van Rhijn, F. K. F. Mensah, S. S. Korevaar et al., "Effects of hypoxia on the immunomodulatory properties of adipose tissue-derived mesenchymal stem cells," Frontiers in Immunology, vol. 4, 2013. 


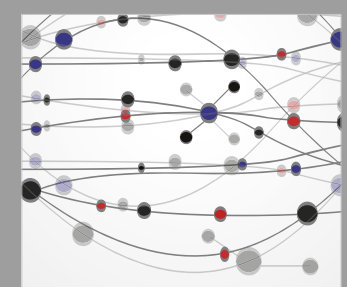

The Scientific World Journal
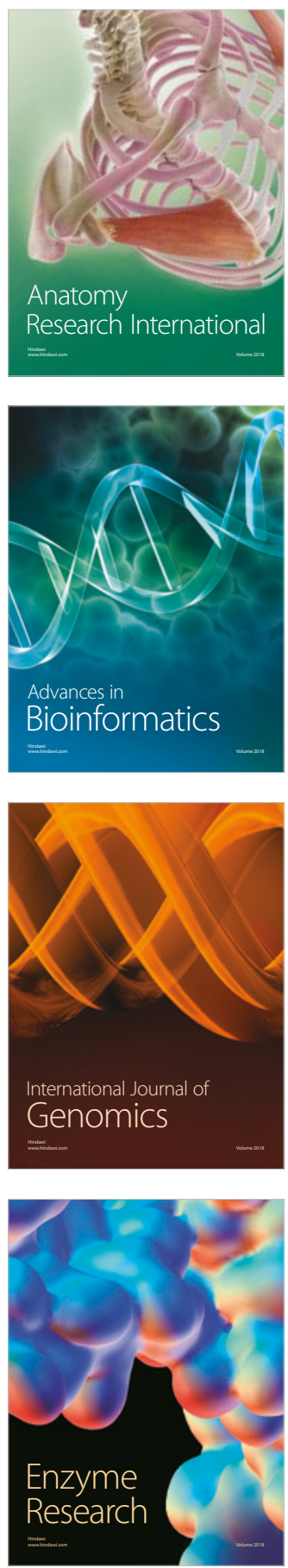
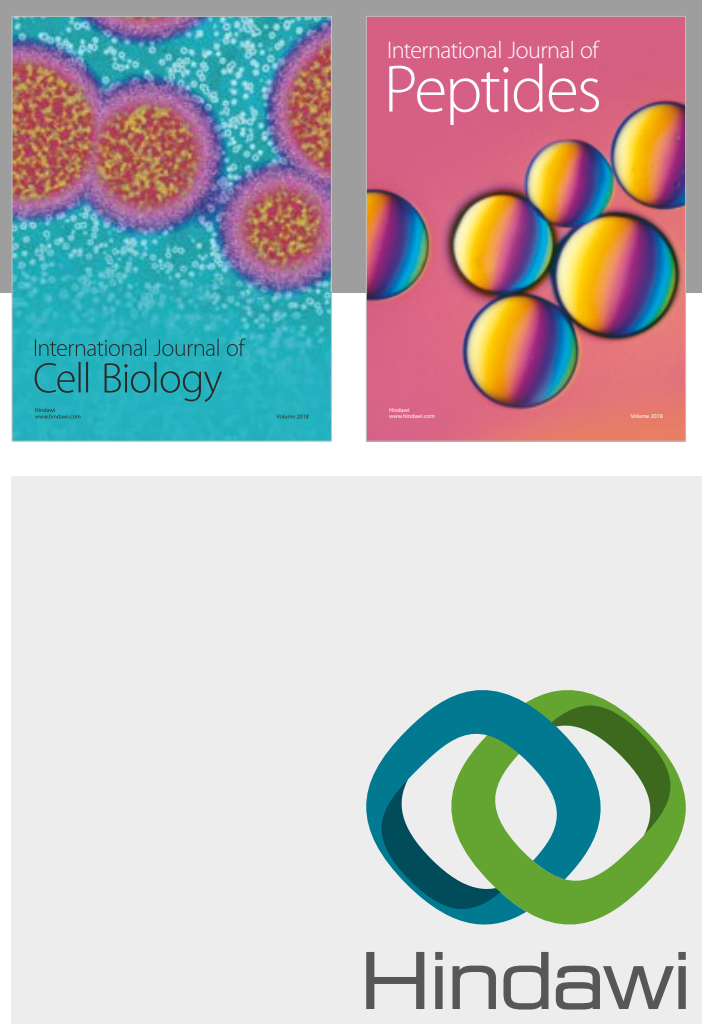

Submit your manuscripts at

www.hindawi.com
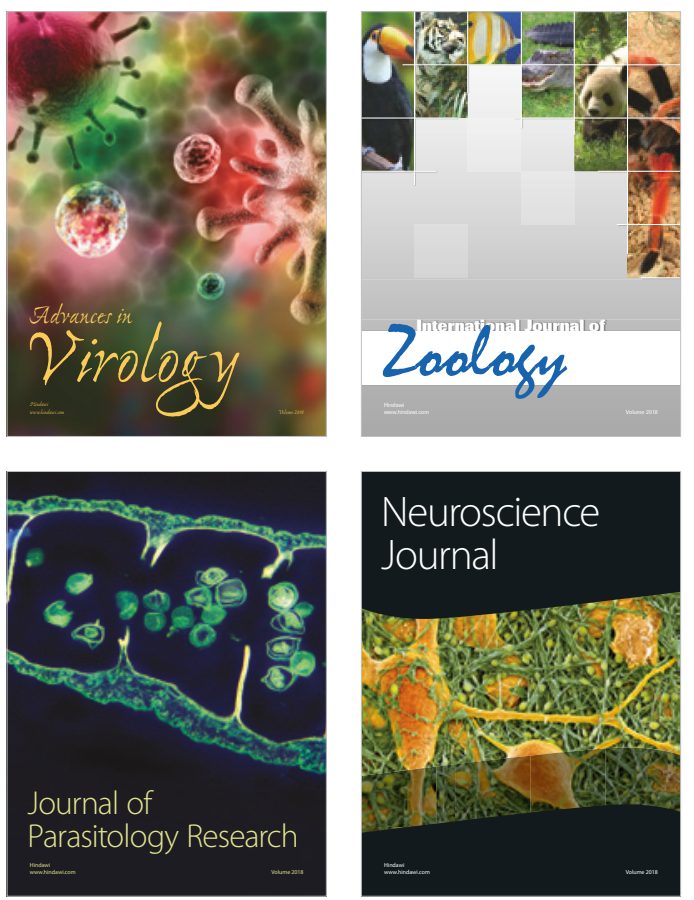
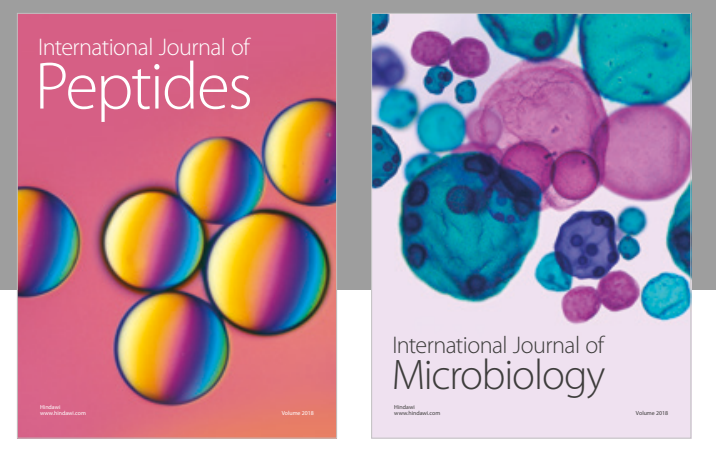

nternational Journal of Microbiology
Journal of
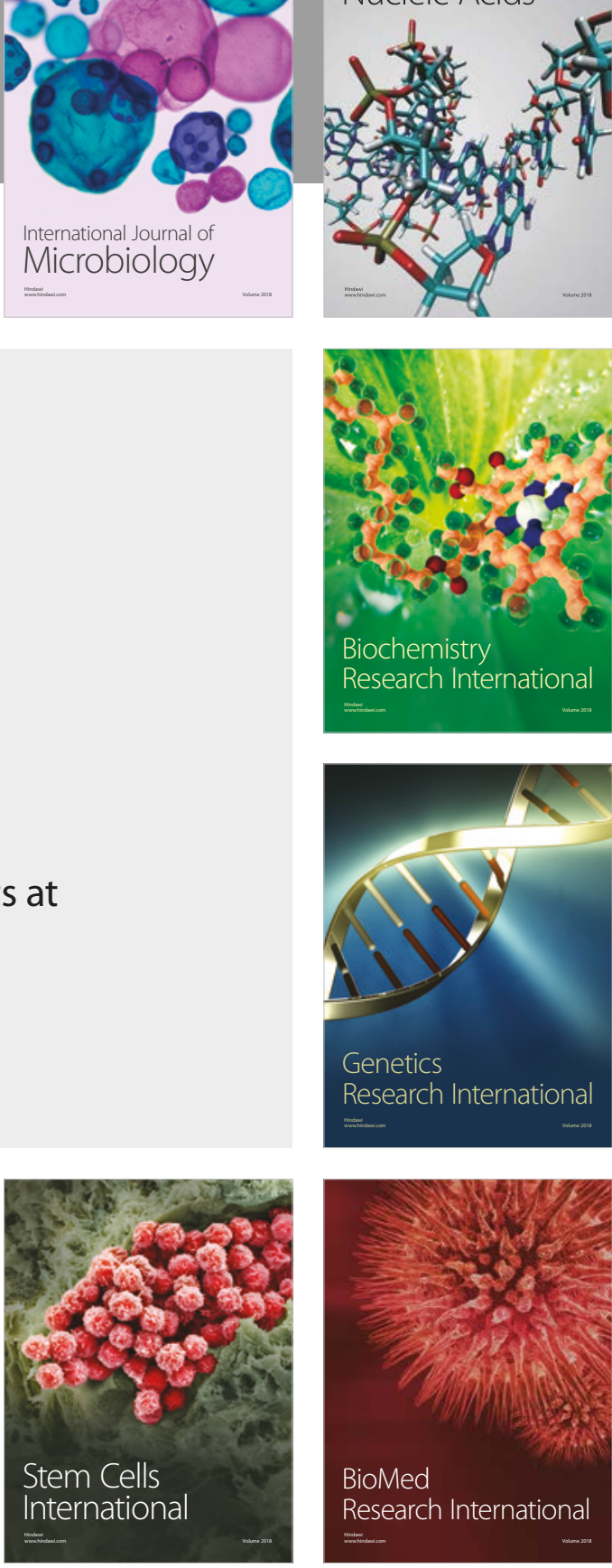
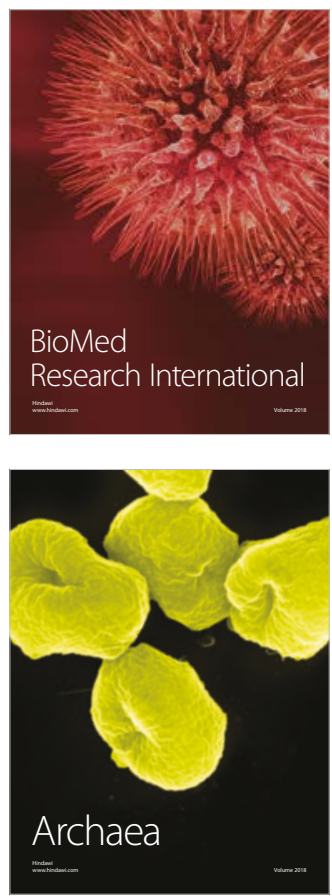